\title{
GAMBARAN PENGELOLAAN DOKUMEN REKAM MEDIS DI PUSKESMAS $X$
}

\author{
Fiqi Nurbaya ${ }^{1}$, Yustika Ayu Okta ${ }^{2}$, Bella Kurnia ${ }^{3}$ \\ Prodi Rekam Medis dan Informasi Kesehatan,FKM,Universitas Bangun Nusantara $(1,2,3)$ \\ Email: fiqinaya@gmail.com ${ }^{1}$, yustikaayu124@gmail.com ${ }^{2}$,bellakurnia1997@gmail.com ${ }^{3}$
}

\begin{abstract}
ABSTRAK
Penyelenggaraan rekam medis untuk mencapai tertib administrasi dan pelayanan kesehatan di rumah sakit maupun puskesmas. Penyelenggaraan rekam medis sangat dibutuhkan sebagai salah satu sarana pelayanan kesehatan. Penelitian ini dilakukan dengan menggunakan studi deskriptif. Tujuan dari penelitian deskriptif menggambarkan sistem pengelolaan dokumen rekam medis puskesmas. Hasil penelitian 1) Sistem penamaan menggunakan identitas asli pasien berupa KTP. 2) Sistem penomoran menggunakan satu nomor untuk pemeriksaan seterusnya. 3) Penjajaran dokumen rekam medis diurutkan berdasarkan kode wilayah pada masing-masing sub rak, dimana dokumen dijajarkan dari angka kecil ke besar. 4) Sistem penyimpanan secara sentralisasi. 5) Retensi dokumen dilakukan secara kondisional. 6) Sistem Pelaporan bersumber dari SP3. 7) Sistem Pengelolaan Dokumen Rekam Medis : assembling, coding, indexing, analysing and reporting, filing.

Kata kunci : puskesmas, dokumen, rekam medis
\end{abstract}

\begin{abstract}
Organization of medical records to achieve orderly administration and health services in hospitals and health centers. Providing medical records is very much needed as a means of health services. This research was conducted using descriptive studies. The purpose of this descriptive study is to describe the management system of Public health center medical record documents. Research result 1) The naming system uses the patient's real identity in the form of a KTP. 2) The numbering system uses one number for subsequent checks. 3) Alignment of medical record documents is sorted by area code on each subshelf, where documents are aligned from small to large numbers. 4) Centralized storage system. 5) Document retention is carried out conditionally. 6) Reporting System sourced from SP3. 7) Medical Records Document Management System: assembling, coding, indexing, analysing and reporting, filing.
\end{abstract}

Keywords: Public health center, documents, medical records 


\section{PENDAHULUAN}

Puskesmas adalah fasilitas
pelayanan kesehatan yang menyelenggarakan upaya pelayanan kesehatan masyarakat dan upaya kesehatan perseorangan tingkat pertama, dengan lebih mengutamakan upaya promotif dan preventif, untuk mencapai derajat kesehatan masyarakat yang setinggitingginya di wilayah kerjanya. (PMK No. 75 Tahun 2014 Pasal 1).

Sejalan dengan arah pembangunan kesehatan untuk lebih meningkatkan jangkauan pelayanan perlu peningkatan sistem rekam medis di seluruh fasilitas pelayanan kesehatan. Tujuan diadakannya penyelenggaraan rekam medis ialah untuk mencapai tertib administrasi dalam pelayanan kesehatan rumah sakit maupun puskesmas. Penyelenggaraan rekam medis dalam suatu instansi kesehatan baik rumah sakit, klinik ataupun puskesmas sangat dibutuhkan sebagai salah satu sarana pelayanan kesehatan dan merupakan sebuah organisasi yang harus diatur sedemikian rupa guna mencapai tujuan yang telah ditetapkan.

Penyelenggaraan sistem rekam medis yang baik, salah satunya harus ditunjang oleh sistem penyediaan berkas rekam medis. Penyediaan berkas rekam medis yang baik adalah penyediaan berkas rekam medis yang cepat, tepat dan efisien. Jika waktu dalam penyediaan rekam medis lama, maka akan menghambat pelayanan kesehatan yang akan diberikan dokter kepada pasien, karena dokter tidak dapat memberikan pelayanan kesehatan kepada pasien tanpa adanya berkas rekam medis pasien tersebut.

\section{METODE}

Penelitian ini dilakukan dengan menggunakan studi deskriptif. Studi deskriptif yaitu penelitian yang memiliki tujuan untuk menjelaskan fenomena, situasi, karakteristik individual, atau kelompok tertentu secara objektif. Tujuan dari penelitian deskriptif adalah menggambarkan peristiwa penting yang terjadi. Pada penelitian ini bermaksud menggambarkan sistem pengelolaan dokumen rekam medis puskesmas.

\section{HASIL}

1. Sistem penamaan

Sistem penamaan menggunakan identitas asli pasien berupa KTP (Kartu Tanda Penduduk) dengan penambahan $\mathrm{Tn} / \mathrm{Ny}$, sebagai acuan pembuatan kartu berobat (KIB). Penulisan gelar kekeluargaan dibedakan dengan :

a. Tuan (Tn) untuk pasien laki-laki yang telah menikah

b. Nyonya (Ny) untuk pasien wanita yang telah menikah

c. Saudara (Sdr) untuk laki-laki $>13$ th dan belum menikah

d. Nona (Nn) untuk wanita $>13$ th dan belum menikah

e. Anak (An) untuk laki-laki/wanita $<13$ th

f. Bayi (By) untuk bayi lakilaki/perempuan 
2. Sistem penomoran

Sistem

penomoran menggunakan satu nomor untuk pemeriksaan seterusnya, dimana satu nomor akan digunakan untuk selamanya setiap kali pasien berkunjung ke puskesmas. Enam digit pertama yang diberikan pada pasien berdasarkan kode wilayah tempat tinggal pasien dan nomor registrasi akan digunakan selamanya untuk seluruh anggota keluarga pasien, sementara setiap individu dalam keluarga tersebut akan dibedakan pada 2 digit terakhir.

$\underbrace{\begin{array}{l|l|l|l|l|l|l|l|}0 & 1 & 2 & 3 & 4 & 5 & 0 & 1 \\ \end{array}} \underbrace{\underbrace{2}}$

Kode Wilayah Nomor Regristrasi Kode Keluarga

\section{Sistem Penjajaran}

Penjajaran dokumen rekam medis diurutkan berdasarkan kode wilayah pada masing-masing sub rak, dimana dokumen dijajarkan dari angka kecil ke besar. Sistem penjajaran menggunakan straight numerical filing (SNF) dengan menjajarkan langsung dokumen sesuai nomor rekam medis, namun ada beberapa form pemeriksaan pasien yang belum terpisah dari map family folder.

\section{Sistem Penyimpanan}

Sistem penyimpanan secara sentralisasi, dimana riwayat kesehatan pasien baik rawat inap maupun rawat jalan dijadikan satu dalam satu folder penyimpanan dokumen.

5. Retensi Penyusutan dan Pemusnahan
Retensi dokumen dilakukan secara kondisional jika dirasa rak cukup penuh dan dokuman cukup banyak. Sudah pernah melakukan retensi terakhir pada Juli 2019 dengan memilah dokumen yang memasuki masa in-aktif kemudian mencatat pada buku daftar pertelaan dokumen rekam medis in-aktif dan memisahkan dokumen tersebut.

6. Sistem Pelaporan

Pelaporan bersumber dari SP3 (Sistem Pencatatan dan Pelaporan)

1) Laporan 10 penyakit terbanyak

2) Fisioterapi

3) Laporan pasien rawat inap

4) Laporan kunjungan gigi

5) Ikhtisar rawat jalan

6) Laporan penyakit indera

7) Laporan penyakit jiwa

8) Laporan kebidanan

9) Laporan kunjungan luar wilayah

10) Laporan laboratorium

11) Laporan kelahiran

12) LB RI

13) Laporan prolanis

14) UKG MD (usaha kesehatan gigi masyarakat desa)

15) UKGS (usaha kesehatan gigi sekolah)

7. Sistem Pengelolaan Dokumen Rekam Medis

1. Assembling

Proses assembling untuk dokumen rawat jalan maupun rawat inap berupa meneliti ketidaklengkapan pengisian yang ditemukan, namun tidak dilakukan penataan urutan dokumen dikarenakan formulir pemeriksaan tidak memiliki 
kode formulir dan tidak adanya SOP yang mengatur urutan formulir yang digunakan, sehingga adanya kendala dalam penetapan dan penyusunan dokumen rekam medis.

2. Coding

Proses $r$ coding
dilakukan langsung oleh
petugas SIMPUS di unit
pelayanan dengan bantuan
petugas kesehatan lainya
seperti dokter, perawat, dan
bidan. Dengan ICD-10
International $\quad$ Statiscal
Clasification Of Disease and
Related Health Problem
Tenth Revision sebagai
acuan dan terintegrasi
dengan primary care, selain
kode penyakit petugas juga
menginputkan kode obat.

3. Indexing

Proses pengindeksan mengunakan sistem komputerisasi yang menjadi satu dengan SIMPUS, proses ini dilakukan untuk mengetahui kasus-kasus yang sedang marak terjadi, agar mendapatkan data 10 besar penyakit setiap bulannya. Selain untuk pengolahan data 10 besar penyakit, indeksing juga menggunakan untuk mengetahui kasus luar biasa yang nantinya akan dilaporkan pada Dinas Kesehatan Kabupaten Sukoharjo.

4. Analysing and Reporting Semua kegiatan di UPTD Puskesmas dicatat dan dilaporkan pada Dinas
Kesehatan Kabupaten

Sukoharjo, laporan yang telah diberikan merupakan gambaran dari hasil kegiatan sehingga meningkatkan kepercayaan pasien serta pemerintah

5. Filing

Proses filing yang
dilakukan berupa petugas
memasang tracer ketika
dokumen diambil dan
mengembalikan dokumen
sesuai dengan nomor rekam
medis yang tertera di tracer.
Pengembalian dokumen
dilakukan ketika dokumen
telah selesai digunakan pada
pelayanan pasien.

\section{PEMBAHASAN}

1. Sistem Penamaan

Menurut Shofari (2004) sistem penamaan merupakan tata cara penulisan nama yang bertujuan untuk membedakan antar pasien. Salah satu sistem pemberian nama adalah nama orang indonesia. Proses identifikasi dan pendokumentasian dokumen pasien, sesuai Shofari (2004) sistem penamaan dapat dilakukan dengan menggunakan kartu identitas yang dimiliki oleh pasien berupa KTP dan dengan nama kepala keluarga. Selain itu, penulisan nama diawal namanya di tambahkan "Ny.", dan "Tn." Untuk pasien pria yang sudah menikah. Keterangan status $\mathrm{Ny} / \mathrm{Tn}$ juga dapat mempermudah petugas dalam memanggil, serta kategori status lainnya. Sistem penamaan ini memudahkan pencatatan serta pencarian dikarenakan pasien pastinya 
membawa dan memiliki kartu identitas.

2. Sistem Penomoran

Sistem penomoran yang digunakan secara Unit Numbering System (UNS) telah sesuai dengan teori Shofari (2004), sistem penomoran ini dipilih karena dengan sistem penomoran ini, nomor yang digunakan tidak akan cepat bertambah banyak, meminimalisir hilangnya banyak data ketika terjadi misfile, selain itu juga berguna dalam data dokumen rekam medis agar terus bersinambungan, juga menghemat sumber daya yang ada. Namun masih ada pasien yang tidak membawa KIB ketika datang ke puskesmas, kemudian petugas melakukan pencarian nomor rekam medis menggunakan nama kepala keluarga atau keluarga yang pernah berobat di puskesmas.

3. Sistem Penjajaran

Sesuai dengan teori Shofari (2004) penggunaan sistem penjajaran secara Straight Numerical Filing (SNF) sangat membantu dan menguntungkan bagi puskesmas, hal ini karena petugas menjadi lebih mudah dalam pengambilan dan pengembalian dokumen dengan tertatanya secara berurutan. Penjajaran dokumen rekam medis pasien pada rak dokumen diurutkan sesuai kode wilayah masing-masing, namun masih ada beberapa dokumen yang letaknya tidak sesuai dengan urutan. Untuk membenahi hal tersebut sedikit demi sedikit dokumen dikembalikan ketempat yang benar dengan meletakkan tracer tempat yang tepat sesuai dengan nomor dokumen yang seharusnya setiap mengambil DRM.

4. Sistem Penyimpanan

Sistem penyimpanan dokumen rekam medis pasien disimpan secara sentralisasi sesuai dengan teori milik Shofari (2004), yaitu dimana dokumen pasien rawat jalan, rawat inap dan gawat darurat diletakan dalam satu map dan ruangan yang sama yang berada di belakang bagian pendaftaran. Hal ini dimaksudkan untuk menghemat biaya dan ruang yang dibutuhkan untuk penyimpanan dokumen, mempercepat proses pelayanan, serta untuk menjaga informasi pasien agar tetap berkesimambungan.

5. Sistem Penyusutan dan Pemusnahan

Penyusutan dokumen rekam medis milik pasien dilakukan kondisional menyesuaikan kebutuhan, apabila dirasa rak penyimpanan sudah mulai penuh dan sesak, retensi akan dilakukan. Sudah pernah melakukan pemusnahan pada tahun 2005 dan terakhir melakukan penyusutan pada bulan Februari 2018.

6. Sistem Pelaporan

Sistem pelaporan terpadu puskesmas menggunakan tahun kalender yaitu bulan Januari sampai bulan Desember dalam tahun yang sama. Sejak April 1992 telah diberitahukan bentuk pelaporan baru yang membedakan antara pelaporan 
dari puskesmas ke Dati II dan Dati II ke Pusat, sedangkan untuk kebutuhan Dati I (Laporan dari Dati II ke Dati I) diberi kesempatan pada setiap Dati I untuk mengembangkan bentuk pelaporan sesuai indikator masing-masing di puskesmas.

a. Mekanisme Laporan

1) Laporan dari puskesmas pembantu dan laporan dari puskesmas keliling, posyandu, dan bidan di desa disampaikan puskesmas yaitu pengelola pencatatan dan pelaporan.

2) Pengelola pencatatan pelaporan menyusun dan mengkomplikasi data yang bersumber dari register-register dan sensus harian.

3) Hasil komplikasi atau olahan dimasukkan ke formulir laporan untuk dikirim oleh puskesmas ke Dinas Kesehatan Dati II.

Hasil olahan dianalisa dan disajikan untuk kepentingan puskesmas dalam mengambil tindakan atau kebijakan.

a. Frekuensi Laporan

1) Laporan Bulanan LB1 (Data Kesakitan), LB2

(Data Kematian), LB3

(Data Obat-obatan) yang baru, dilakukan setiap bulan dan paling lambat dikirim ke Dinas Dati II tanggal 10 bulan berikutnya.

2) Laporan Triwulan yaitu format laporan triwulan dilaporkan tanggal 10 pada bulan yang bersangkutan ke Dinas Kesehatan Dati I.

3) Laporan Tahunan terdiri dari LSD1 (Data Umum, Fasilitas), LSD2 (Data Sarana), LSD3 (Data Tenaga), dilaporkan paling lambat tanggal 10 Januari tahun berikutnya. Laporan ini hanya dilaporkan satu kali saja.

7. Sistem Pengelolaan Dokumen Rekam Medis

Pengelolaan dokumen rekam medis pasien melakukan assembling pengecekan kelengkapan pengisian formulir pada pasien rawat inap dan rawat jalan, dokumen pasien rawat jalan yang telah selesai pelayanan dan dokumen pasien rawat inap yang telah selesai proses assembling pengecekan kelengkapan isi akan langsung dikembalikan pada rak penyimpanan dokumen. Hal ini dikarenakan Puskesmas tidak memiliki jenis formulir lainnya selain yang saat ini digunakan.

Proses pengkodean diagnosa penyakit dan obat yang diberikan pada pasien dilakukan dengan melihat riwayat pasien pada DRM dan dilakukan oleh petugas unit pelayanan oleh dokter terkait serta langsung diinputkan pada SIMPUS, dengan ICD 10 sebagai acuan. Penyimpanan dokumen rekam medis pasien (filing) yang letaknya dibelakang bagian pendaftaran tertata sangat rapi dengan tracer yang memudahkan pengembalian dokumen. 


\section{KESIMPULAN}

1. Penggunaan Unit Numbering System (UNS) sebagai sistem penamaan pasien sesuai dengan kartu identitas milik pasien dengan penambahan kode wilayah diawal dan kode anggota keluarga diakhir. Sistem penjajaran yang digunakan secara Straight Numbering Filing (SNF) dan sistem penyimpanan secara sentralisasi.

2. Sistem pengelolahan dokumen rekam medis pasien belum sesuai dengan prosedur seharusnya yang dikemukakan oleh Shofari (2004) dimana pengelolahan dokumen rekam medis dimulai dari assembling, coding, indexing, analisyng reporting, dan filing. Karena pada proses assembling belum adanya SOP yang mengatur urutan formulir yang digunakan.

\section{DAFTAR PUSTAKA}

Dindatia, Novi; Junaid; Rasama. 2017. Gambaran Kinerja Petuga Rekam Medik di Rumah Sakit Umum Daerah Kota Kendari Tahun 2017. Jurnal Ilmiah Mahasiswa Kesehatan Masyarakat Vol 2 No 6

Giyana, F. 2012. Analisis Sistem Pengelolaan Rekam Medis Rawat Inap Rumah Sakit Umum Daerah Kota
Semarang. Jurnal Kesehatan Masyarakat Vol 1 No 2

Kemenkes RI Nomor

129/Menke/SK/II/2008

Tentang Standart Pelayanan

Rumah sakit

Notoatmodjo, S. 2012. Metodologi

Penelitian Kesehatan. Jakarta:

PT Rineka Cipta

Nursalam, 2013. Konsep dan

Penerapan Metodologi

Penelitian Keperawatan.

Salemba Medica: Jakarta

Peraturan Menteri Kesehatan Nomor 269/MENKES/PER/III/2008

Tentang Rekam Medis.

Peraturan Menteri Kesehatan Republik Indonesia Nomor 43 Tahun 2019 Tentang Pusat Kesehatan Masyarakat

Shofari, Bambang. 2004. Pengelolaan Sistem Rekam Medis. Semarang: PORMIKI

Sibagariang. 2010. Buku Saku Metodologi Penelitian Ilmu Keperawatan. Jakarta: Salemba Medika

Sudra, IR.2014. Rekam Medis. Tanggerang Selatan: UI

Yovita, Maria; Uswatun Hasanah; Reni Chairunnisah. 2019. Gambaran Waktu Penyediaan Dokumen Rekam Medis di Puskesmas Karang Pule Kota Mataram. Jurnal Rekam Medis dan Informasi Kesehatan Vol 2 No 2 